\title{
Photosynthetic response of poikilochlorophyllous desiccation-tolerant Pleurostima purpurea (Velloziaceae) to dehydration and rehydration
}

\author{
S.T. AIDAR ${ }^{*,+}$, S.T. MEIRELLES ${ }^{* *}$, R.F. OLIVEIRA ${ }^{* * *}$, A.R.M. CHAVES ${ }^{*}$, \\ and P.I. FERNANDES-JÚNIOR*
}

Centro de Pesquisa Agropecuária do Trópico Semiárido, Empresa Brasileira de Pesquisa Agropecuária - Embrapa, Petrolina, PE, CEP 56302-970, Brazil

Departamento de Ecologia Geral, Instituto de Biociências, Universidade de São Paulo, São Paulo, SP, CEP 05508-090, Brazil**

Departamento de Ciências Biológicas, Escola Superior de Agricultura Luiz de Queiroz, Universidade de São Paulo, São Paulo, SP, CEP 13418-900, Brazil ${ }^{* * *}$

\begin{abstract}
The poikilochorophyllous, desiccation-tolerant (PDT) angiosperm, Pleurostima purpurea, normally occurs in less exposed rock faces and slightly shady sites. Our aim was to evaluate the light susceptibility of the photosynthetic apparatus during dehydration-rehydration cycle in $P$. purpurea. In a controlled environment, the potted plants were subjected to water deficit under two different photosynthetic photon flux densities [PPFD, 100 and $400 \mu \mathrm{mol}$ (photon) $\mathrm{m}^{-2} \mathrm{~s}^{-1}$ ]. In the higher PPFD, net photosynthetic rate $\left(P_{\mathrm{N}}\right)$ become undetectable after stomata closure but photochemical efficiency of photosystem II, electron transport rate, and photochemical quenching coefficient were maintained relatively high, despite a partial decrease. The photochemical activity was inhibited only after the complete loss of chlorophylls, when leaf relative water content dropped below $72 \%$ and total carotenoids reached maximal accumulation. Nonphotochemical energy dissipation increased earlier in response to dehydration under higher PPFD. $P_{\mathrm{N}}$ and photochemical activity were fully recovered after rehydration under both light treatments. Our results suggested that the natural occurrence of $P$. purpurea should not be restricted by the light intensity during the complete desiccation-rehydration cycles.
\end{abstract}

Additional key words: chlorophyll fluorescence; gas exchange; photoprotective mechanisms; vegetative desiccation tolerance.

\section{Introduction}

Vascular, desiccation-tolerant (DT) plants, also named poikilohydrics or resurrection plants, endure their vegetative tissue dehydration with losses of more than $90 \%$ of the relative water content (RWC) without irreversible injuries. Dehydration is usually followed by leaf folding and contraction together with color changes and rigidness (Meirelles et al. 1997). The desiccated tissues return to their normal appearance and physiology within hours or few days after rehydration, depending on the species (Sherwin and Farrant 1996, Tuba et al. 1998).

During the dehydration-rehydration cycle, cellular mechanisms of protection and repair are induced, conferring the DT phenotype. Accumulation of solutes, synthesis of compounds that maintain membranes and

Received 18 December 2012, accepted 8 August 2013.

${ }^{+}$Corresponding author; phone: 5587 38663773, fax: 5587 38663815, e-mail: saulo.aidar@embrapa.br

Abbreviations: ATP - adenosine triphosphate; Car - carotenoids; Chl - chlorophyll; $\mathrm{CO}_{2}$ - carbon dioxide; DD - days of deficit; $\mathrm{DR}$ - days of rehydration; DT - desiccation tolerant; $E$ - transpiration; ETR - electron transport rate through the PSII; $\mathrm{F}_{\mathrm{m}}-$ maximum fluorescence of the dark-adapted sample; $F_{m}{ }^{\prime}-$ maximum fluorescence of the light-adapted sample; $F_{s}-$ steady fluorescence; $F_{v} / F_{m}-$ maximum photochemical efficiency of PSII; $\mathrm{F}_{\mathrm{v}}{ }^{\prime} / \mathrm{F}_{\mathrm{m}}{ }^{\prime}$ - intrinsic photochemical efficiency of PSII; $\mathrm{F}_{0}$ - minimal fluorescence of the darkadapted sample; $\mathrm{F}_{0}{ }^{\prime}-$ minimal fluorescence of the light-adapted sample; $g_{\mathrm{s}}$ - stomatal conductance; HDT - homoiochorophyllous desiccation tolerant; HR - hours of rehydration; IR100 - PPFD of $100 \mu \mathrm{mol} \mathrm{m}{ }^{-2} \mathrm{~s}^{-1}$; IR400 - PPFD of $400 \mu \mathrm{mol} \mathrm{m}^{-2} \mathrm{~s}^{-1}$; IRGA infrared gas analyzer; LCF - leaf chamber fluorometer; NPQ - Stern-Volmer nonphotochemical quenching; ${ }^{1} \mathrm{O}_{2}$ - superoxide radical; $P_{\mathrm{N}}$ - net photosynthetic rate; PCO - photorespiratory carbon oxidation; PDT - poikilochorophyllous desiccation tolerant; PPFD photosynthetic photon flux density; PS - photosystem; PVC - polyvinyl chloride; qN - nonphotochemical quenching coefficient; $\mathrm{q}_{\mathrm{P}}$ - photochemical quenching coefficient; ROS - reactive oxygen species; Rubisco - ribulose-1,5-bisphosphate carboxylase/oxygenase; RuBP - ribulose-1,5-bisphosphate; RWC - relative water content; SD - standard deviation; $x+c$ - xanthophylls and $\beta$-carotenes; $\Phi_{\mathrm{PSII}}$ - actual photochemical efficiency of PSII.

Acknowledgements: The authors are thankful to the Fundação de Amparo à Pesquisa do Estado de São Paulo (FAPESP) and to the Coordenação de Aperfeiçoamento de Pessoal de Nível Superior (CAPES) which provided scholarships to S.T. Aidar. 
macromolecules integrity, and activation of antioxidant systems are among the most studied, protective mechanisms against osmotic, mechanical, and oxidative stress during dehydration (Rascio and La Rocca 2005).

Light can become excessive during the water deficit. Stomata closure limits $\mathrm{CO}_{2}$ diffusion and restricts photosynthetic use of absorbed light energy and it leads to the formation of reactive oxygen species (ROS) (Dinakar et al. 2012). Generation of ROS can damage oxygen-evolving complex of photosystem (PS) II and the PSII reaction centers and inhibit photosynthesis (Smirnoff 1993). DT angiosperms avoid the toxic build-up of ROS by controlling the metabolism and they cease photosynthesis during desiccation (Sherwin and Farrant 1998). For this purpose, the DT plants perform two different strategies to deal with light in the desiccated state: (1) homoiochlorophyllous (HDT) plants maintain chlorophyll (Chl) content stable without major changes in the chloroplast membrane systems; and (2) poikilochlorophyllous (PDT) plants dismantle the chloroplast membrane systems and loose completely leaf $\mathrm{Chl}$ during dehydration and they restore all systems during the rehydration phase (Hambler 1961, Farrant et al. 2003). Nevertheless, both groups show increased activity of antioxidant enzymes and anthocyanin accumulation (Sherwin and Farrant 1998).

Although contrasting, the HDT and PDT plants constitute different strategies how to avoid damaging light-Chl interaction in the desiccated state and minimize free radical formation (Tuba et al. 1998, Farrant et al. 2003). The HDT plants are normally found at shady sites where leaf folding in their dried state complements the necessary shading to protect $\mathrm{Chl}$ from light. In this group, the highly preserved chloroplasts in the dried state allow the quick recovery of photosynthesis when moisture becomes available again (Péli et al. 2012) and only short wet periods to grow starts. On the other hand, the profound modifications of the PDT chloroplasts during dehydration require longer recovery time after rehydration. This strategy is obligatory for the plants that must endure several months in the dried state under high irradiance (Sherwin and Farrant 1996, Tuba et al. 1998, Tuba and Lichtenthaler 2011).

In the HDT species, the ability to halt and recover

\section{Materials and methods}

Plant material and culture condition: Eight-year-old (mature), potted individuals of $P$. pupurea (Hook.) Raf. (Velloziaceae) were grown according to Aidar et al. (2010). The plants were transferred to a growth chamber (Fitotron PGR15, Conviron, Canada) under a day/night cycle of $12 / 12 \mathrm{~h}$ with a PPFD of $400 \mu \mathrm{mol} \mathrm{m}{ }^{-2} \mathrm{~s}^{-1}$ (IR400) at the leaf level (using both cool white fluorescent and incandescent lamps), $25^{\circ} \mathrm{C}$ temperature and $55-65 \%$ of relative humidity. Pots were watered daily up to field capacity using tap water applied directly in the soil, eventually wetting the leaves, during $60 \mathrm{~d}$ before the water-deficit treatment started. photosynthetic activity during the dehydration-rehydration cycle was proved to be dependent on the light levels (Degl'Innocenti et al. 2008, Georgieva et al. 2008). On the other hand, the PDT strategy has been less explored, namely the effects of light upon the physiological responses during the dehydration-rehydration cycle. The main studies concerning the PDT species and their response to light were done with south and southwestern Africa species. They were focused mainly on various mechanisms, such as leaf movement, changes in protective pigments, and the activity of some antioxidant enzymes, which would minimize damage caused by excessive light (Sherwin and Farrant 1998, Farrant et al. 2003).

Dicotyledons and ferns are always the HDT plants; monocotyledons include both types of the DT strategies (Tuba and Lichtenthaler 2011). Most of the PDT plants are comprised of Velloziaceae species, but the group involves also Cyperaceae, Anthericaceae, and Poaceae species (Tuba and Lichtenthaler 2011). In Brazil, the PDT plants are frequent at rock outcrops with occurrences registered in the southeastern region (Meirelles et al. 1999), the northeastern "Caatinga" (dry tropical forest) (Gaff 1987), and the Midwest "Cerrado" (Brazilian neotropical savanna) (Meirelles et al. 1997).

$P$. purpurea is the PDT, monocotyledon plant, endemic at rock outcrops of the Rio de Janeiro State, Brazil (Meirelles et al. 1997). The aim of this work was to evaluate the susceptibility of the photosynthetic apparatus of $P$. purpurea to different light intensities during dehydration-rehydration cycle. Contrary to other PDT species found in similar areas, $P$. purpurea normally occurs at less exposed rock faces and slightly shady sites. This raised the question if the interaction between light intensity and desiccation could be determinant to restrict its sites of occurrence. Our basic hypothesis was that photosynthetic ability during the recovery phase is not limited by the light regime during the dehydration phase. To test this, Chl fluorescence and gas-exchange analysis together with water status and photosynthetic pigment quantification in leaf tissues were determined during dehydration and rehydration in intact plants under two different light intensities.

Leaf curling was expected during water stress, because it reduces irradiation reaching the leaf surface. To prevent this interference, transparent plastic tabs were carefully positioned on the new, completely expanded leaves, aiming to maintain them fully opened and directly exposed to the light source (with the aid of rigid wires inserted at the edges of the pots). The tabs were constructed with transparent semirigid stripes of polyvinyl chloride (PVC) $(0.3 \mathrm{~mm}$ thick $)$, of $15 \times 5 \mathrm{~cm}$ with holes of $6 \mathrm{~mm}$ in a diameter along the extension. At the leaf surface, the incident PPFD was reduced by covering the transparent tab with a screen of black nylon (75\%). This resulted in values 
of around $100 \mu \mathrm{mol} \mathrm{m} \mathrm{m}^{-2} \mathrm{~s}^{-1}$ of PPFD (IR100) at the upper leaf level, while the tabs without cover allowed IR400 at the leaf surface. All plastic tabs were installed $15 \mathrm{~d}$ before measurements started to allow leaf acclimation to the specific light intensity.

At the beginning, all the measurements were carried out on the leaves not detached of the intact plants under a fully hydrated condition (control) throughout dehydration and the rehydration phase. The water deficit was imposed by suspension of irrigation for $54 \mathrm{~d}$ (days of deficit, DD), because the PDT species are frequently subjected to drought periods of several months. This period was long enough to expose the plants substantially to the light regime in order to evaluate the effects during the desiccated state. This period was compatible with the drought periods experienced by $P$. pupurea in its natural habitats. Then, the rehydration phase started with daily watering up to field capacity by using tap water applied directly to the soil, eventually wetting the leaves. The rehydration treatment was carried out under continuous light during the first $24 \mathrm{~h}$. Following this treatment, the standard, 12/12 h of light/dark photoperiod was maintained, the same cycle as at the beginning of the experiment, for 8 days.

Gas exchange and $\mathrm{Chl}$ fluorescence: Net photosynthetic rate $\left(P_{\mathrm{N}}\right)$, transpiration $(E)$ and stomatal conductance $\left(g_{\mathrm{s}}\right)$ were measured with an infrared gas analyzer IRGA (Portable Photosynthesis System LI-6400, LI-COR Inc., Lincoln, NE, USA) and calculated according to von Caemmerer and Farquhar (1981). Chl fluorescence induction kinetics was performed with a Leaf Chamber Fluorometer (LI-6400-40, LI-COR Inc., Lincoln, NE, USA) coupled to the IRGA. To simulate predawn conditions, minimal fluorescence of the dark-adapted sample $\left(\mathrm{F}_{0}\right)$ was always determined before the beginning of the light period. Then maximal fluorescence $\left(\mathrm{F}_{\mathrm{m}}\right)$ was measured using saturation pulse $\left(5,000 \mu \mathrm{mol} \mathrm{m} \mathrm{m}^{-2} \mathrm{~s}^{-1}\right.$ PPFD, $0.8 \mathrm{~s}$ duration) and maximal quantum yield of PSII $\left(\mathrm{F}_{\mathrm{v}} / \mathrm{F}_{\mathrm{m}}\right)$ was calculated as $\left(\mathrm{F}_{\mathrm{m}}-\mathrm{F}_{0}\right) / \mathrm{F}_{\mathrm{m}}$ (Kitajima and Butler 1975).

The measurements of gas exchange and Chl $a$ fluorescence in samples adapted to light were conducted always $2 \mathrm{~h}$ after the beginning of the light period on the same leaves sampled in the predawn measurements. Gas exchange was measured under steady-state conditions after positioning the leaf in the $I R G A$ chamber adjusted previously with the same PPFD of the leaf light treatment (IR400 or IR100). The steady-state fluorescence $\left(\mathrm{F}_{\mathrm{s}}\right)$ was measured under the continuous irradiation, followed by the application of a $2^{\text {nd }}$ saturation pulse for $0.8 \mathrm{~s}$ to determine the maximum fluorescence $\left(\mathrm{F}_{\mathrm{m}}{ }^{\prime}\right)$ of the light-adapted sample. After the actinic light was turned off and the minimal fluorescence of the light-adapted sample $\left(\mathrm{F}_{0}{ }^{\prime}\right)$ was determined, the leaf tissue was exposed to far red light of $740 \mathrm{~nm}$ for $3 \mathrm{~s}$. The fluorescence parameters were used to calculate the intrinsic and effective quantum yield $\left(\mathrm{F}_{\mathrm{v}}{ }^{\prime} / \mathrm{F}_{\mathrm{m}}{ }^{\prime}\right.$ and $\Phi_{\mathrm{PSII}}$, respectively), electron transfer rate (ETR) (Genty et al. 1989), photochemical quenching ( $\left.\mathrm{q}_{\mathrm{p}}\right)$ (Kooten and Snel 1990), Stern-Volmer-type nonphotochemical quenching (NPQ) (Bilger and Björkman 1990), and nonphotochemical quenching coefficient $\left(\mathrm{q}_{\mathrm{N}}\right)$ (Kooten and Snel 1990).

Leaf and plant-soil relative water content: The leaf relative water content (RWC) was measured in detached leaves, other than those used for gas-exchange measurements. The leaves of similar rosette position and radiation exposure (IR400) were collected immediately after gas-exchange and fluorescence measurements. Sections of about $2 \mathrm{~cm}$ length were excised from the middle part of the leaf blade. Thereafter, the leaf sections were cut along the midrib resulting in two symmetric half pieces. One of them was used to estimate RWC; another was used for pigment extraction. Leaf RWC and plant-soil RWC were calculated according Turner (1981). These variables were estimated as the mass of the fully watered leaf piece or plant-soil unit (TM - saturated, "turgid" mass), in relation to the instantaneous mass attained for these samples throughout the experiment (FM - fresh mass) and to the lowest constant mass attained for these samples after water withdrawal (DM - dry mass). The RWC was calculated according Turner (1981) as $[(\mathrm{FM}-\mathrm{DM}) /(\mathrm{TM}-\mathrm{DM})] \times 100]$. Leaf instantaneous FM was taken before saturation. The saturation state was attained by floating leaf piece on distilled water. Leaf DM was measured after oven-drying overnight at $80^{\circ} \mathrm{C}$. The plant-soil RWC was only the approximate value of the soil water status to have the reference of water lost during the dehydration process. The fully watered, plant-soil mass was taken after dipping the potted plant in water for $3 \mathrm{~h}$ and draining for $6 \mathrm{~h}$. The instantaneous mass during the dehydration treatment was considered the FM of the potted plant. The minimum plant-soil DM was the lowest constant mass attained after water withdrawal.

Pigment extraction and quantification: Pigments were extracted from leaf sections in ethanol (96\%). The leaf samples, collected immediately after gas-exchange and fluorescence measurements, were ground with pestle and mortar with some ethanol, then the remaining material and extracted pigments were suspended to $10 \mathrm{~mL}$ with the same ethanol used in the extraction. The suspension was centrifuged (3,000 rpm- for $300 \mathrm{~s})$ and the pellet discarded. The absorbance of the supernatant was determined spectrophotometrically at $665,649,470 \mathrm{~nm}$ and used, respectively, to calculate chlorophyll (Chl) $a$ and $\mathrm{Chl} b$, and carotenoids (Car) concentration (including xanthophylls and $\beta$-carotenes, $x+c$ ), according to Lichtenthaler and Wellburn (1983). Total Chl $(a+b)$ was obtained by the sum of Chl $a$ and $\mathrm{Chl} b$. The concentration was expressed in $\left[\mu \mathrm{g} \mathrm{g}^{-1}(\mathrm{DM})\right]$. All procedures for determination of photosynthetic pigments followed Aidar et al. (2010). 
Experimental design and statistical analysis: The experiments were carried out in a completely randomized design. Four tabs, two transparent and two shaded, were allocated on four different leaves of each plant, in total of three plants (replications) per treatment. For the leaf gas exchanges and $\mathrm{Chl} a$ fluorescence, 6 replications were used under each irradiance. The other evaluations included

\section{Results}

The plant-soil RWC decreased promptly after ceasing watering. Leaf RWC values were higher than $70 \%$ until the plant-soil RWC reached 25\% (10 DD; Fig. 1A). During 3 additional DD, the leaf RWC decreased to $16 \%$ (Fig. $1 A$ ). After 55 DD, leaf RWC reached 6\% (Fig. 1B). After $12 \mathrm{~h}$ only 3 replications (1 leaf per plant). Means and standard deviation (SD) were determined and compared by the analysis of variance ( $A N O V A$ ) procedure using the Tukey's test for multiple comparisons. A $5 \%$ of significance $(p<0.05)$ level was used as statistically significant difference for result interpretation.

of rehydration (HR), the plant-soil RWC reached values near those of the control conditions (Fig. $2 B$ ).

During the progress of dehydration, Chl $a$ and $\mathrm{Chl} b$ were maintained stable up to $10 \mathrm{DD}$ (Fig. $2 A$ ). At this point, the leaves were partially rolled downwards along the

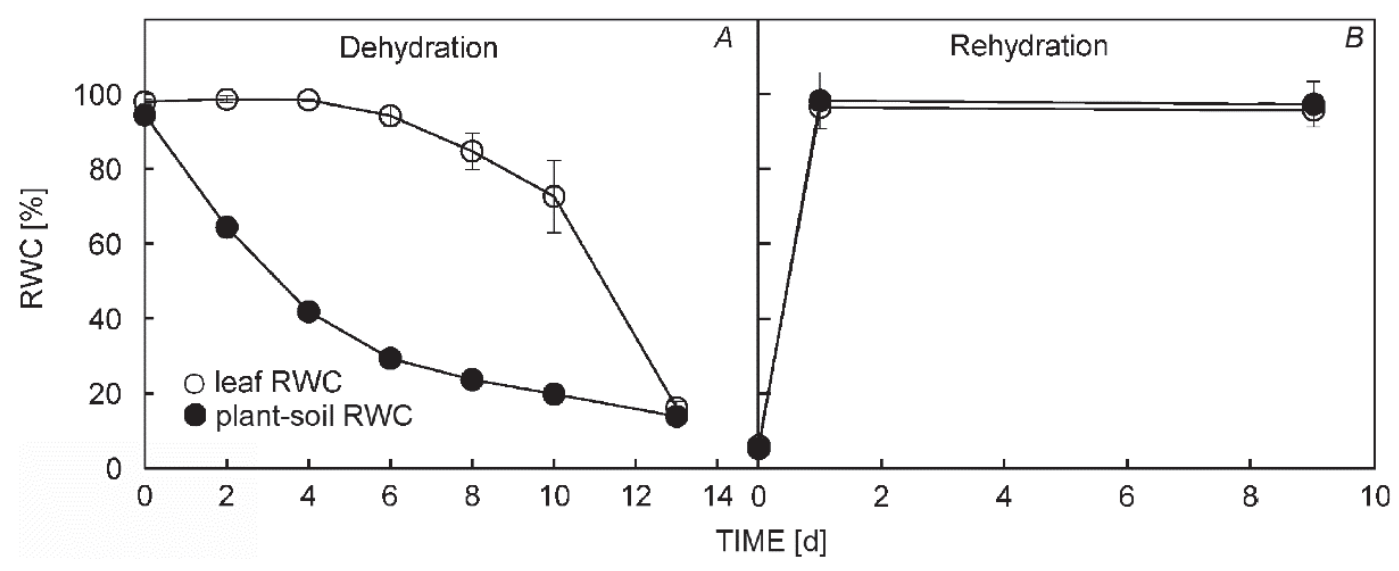

Fig. 1. Time progression of relative water content (RWC) in plant-soil (solid circles) and leaf pieces (open circles) of $P$. purpurea during dehydration $(A)$ and rehydration $(B)$ phases. Means $\pm \mathrm{SD}, n=3$.

midrib. After this stage, the leaves turned yellow with the complete loss of Chl. It coincided with the period of the highest leaf dehydration and strong leaf rolling. The Car content increased about 7 times (Fig. 2C) during the entire dehydration period.

After 24 HR of rehydration (DR), leaves recovered $c a$. $64 \%$ of the control Chl content (Fig. 2B). Complete recovery of $\mathrm{Chl}(a+b)$ content was reached after 9 days (Table 1). During the same period, Car decreased progressively, but maintained the concentration about 3 times larger compared with the control conditions (Fig. 2D, Table 1).

In the control condition, the $P_{\mathrm{N}}$ average was $8.7 \mu \mathrm{mol}$ $\mathrm{m}^{-2} \mathrm{~s}^{-1}$ under the IR400, a value 6 times larger than that observed under IR100 (Fig. $3 A$ ). After water withdrawal, $P_{\mathrm{N}}$, $g_{\mathrm{s}}$, and $E$ showed a partial decrease even when the leaf RWC was still 98\%, while plant-soil RWC was $42 \%$ (Fig. 1A). When leaf and plant-soil RWC reached $94 \%$ and $29 \%$, respectively, $P_{\mathrm{N}}$ became slightly negative. Then, $P_{\mathrm{N}}$ was maintained around zero (Fig. $3 A$ ) up to the maximum dehydration of leaf tissues (6\% of RWC) (Fig. 1A). After
12 HR under continuous light ( $1^{\text {st }}$ day), $P_{\mathrm{N}}$ became initially negative (Fig. $3 B$ ), corresponding to a respiration phase, even with values of $g_{\mathrm{s}}$ and $E$ around zero (Fig. $3 D$ ). Within $24 \mathrm{HR}, P_{\mathrm{N}}$ became positive (Fig. $3 B$ ) with a low increase in $g_{\mathrm{s}}$ (Fig. $3 D$ ) and $E$ (Fig. $3 F$ ). The maximum recovery of $P_{\mathrm{N}}($ Fig. $3 B), g_{\mathrm{s}}($ Fig. $3 D)$, and $E$ (Fig. $3 F$ ) was observed on 9 DR.

The maximum $\left(\mathrm{F}_{\mathrm{v}} / \mathrm{F}_{\mathrm{m}}\right.$, Fig. $\left.4 A\right)$, intrinsic $\left(\mathrm{F}_{\mathrm{v}}{ }^{\prime} / \mathrm{F}_{\mathrm{m}}{ }^{\prime}\right.$, Fig. 4C), and actual ( $\Phi_{\text {PSII }}$, Fig. 4E) photochemical efficiencies of PSII, and the electron transport rate (ETR) (Fig. $4 G$ ) showed a dual phase pattern of decreasing before the establishment of apparently anabiotic state.

After suspension of irrigation, these parameters were maintained high as long as any $P_{\mathrm{N}}$ occurred. With $P_{\mathrm{N}}$ cessation on $6 \mathrm{DD}, \mathrm{F}_{\mathrm{v}}{ }^{\prime} / \mathrm{F}_{\mathrm{m}}{ }^{\prime}, \Phi_{\mathrm{PSII}}$ and ETR decreased only partially and established a new phase of stable values that were maintained until $10 \mathrm{DD}$. This decrease was more pronounced under IR400.

$\mathrm{F}_{\mathrm{v}} / \mathrm{F}_{\mathrm{m}}$ decrease started first under IR400. All the fluorescence parameters decreased to zero after $10 \mathrm{DD}$. It was accompanied by the complete loss of Chl. 
Table 1. Comparisons of physiological parameters of $P$. purpurea before suspension of water supply (control) and after recovery from desiccation ( $9 \mathrm{~d}$ of rehydration) under photosynthetic photon flux densities (PPFD) of $400 \mu \mathrm{mol} \mathrm{m} \mathrm{m}^{-2} \mathrm{~s}^{-1}$ and $100 \mu \mathrm{mol} \mathrm{m} \mathrm{m}^{-2} \mathrm{~s}^{-1}$. Means \pm SD followed by different superscript letter in the same row are significantly different $(p<0.05)$. RWC - relative water content; Chl chlorophyll; Car - carotenoids; $P_{\mathrm{N}}-$ net photosynthetic rate; $g_{\mathrm{s}}-$ stomatal conductance; $E$ - transpiration; $\mathrm{F}_{\mathrm{v}} / \mathrm{F}_{\mathrm{m}}-\mathrm{maximum}$ photochemical efficiency of PSII; $\mathrm{F}_{\mathrm{v}}{ }^{\prime} / \mathrm{Fm}_{\mathrm{m}}$ - intrinsic photochemical efficiency of PSII; ФPSII - actual photochemical efficiency of PSII; qP - photochemical quenching coefficient; qN - nonphotochemical quenching coefficient; NPQ - Stern-Volmer nonphotochemical quenching; ETR - electron transport rate through the PSII.

\begin{tabular}{|c|c|c|c|c|}
\hline PPFD & & Control & After recovery & $\%$ of recovery \\
\hline $400\left[\mu \mathrm{mol} \mathrm{m}^{-2} \mathrm{~s}^{-1}\right]$ & $\begin{array}{l}\text { Leaf RWC }[\%] \\
\text { Chl }(a+b)\left[\mu \mathrm{g} \mathrm{g}^{-1}\right] \\
\mathrm{Car}\left[\mu \mathrm{g} \mathrm{g}^{-1}\right] \\
P_{\mathrm{N}}\left[\mu \mathrm{mol}\left(\mathrm{CO}_{2}\right) \mathrm{m}^{-2} \mathrm{~s}^{-1}\right] \\
g_{\mathrm{s}}\left[\mathrm{mol}\left(\mathrm{H}_{2} \mathrm{O}\right) \mathrm{m}^{-2} \mathrm{~s}^{-1}\right] \\
E\left[\mathrm{mmol}_{2}\left(\mathrm{H}_{2} \mathrm{O}\right) \mathrm{m}^{-2} \mathrm{~s}^{-1}\right] \\
\mathrm{F}_{\mathrm{v}} / \mathrm{F}_{\mathrm{m}} \\
\mathrm{F}_{\mathrm{v}} / \mathrm{F}_{\mathrm{m}} \\
\Phi_{\text {PSII }} \\
\mathrm{qP}_{\mathrm{P}} \\
\mathrm{q}_{\mathrm{N}} \\
\text { NPQ } \\
\text { ETR }\left[\mu \mathrm{mol} \mathrm{m}^{-2} \mathrm{~s}^{-1}\right]\end{array}$ & $\begin{array}{l}97.96 \pm 0.7^{\mathrm{a}} \\
1537.23 \pm 111.25^{\mathrm{a}} \\
31.07 \pm 2.42^{\mathrm{a}} \\
8.57 \pm 2.596^{\mathrm{a}} \\
0.147 \pm 0.083^{\mathrm{a}} \\
2.08 \pm 1.05^{\mathrm{a}} \\
0.81 \pm 0.012^{\mathrm{a}} \\
0.57 \pm 0.08^{\mathrm{a}} \\
0.27 \pm 0.042^{\mathrm{a}} \\
0.47 \pm 0.032^{\mathrm{a}} \\
0.62 \pm 0.244^{\mathrm{a}} \\
1.4 \pm 1.05^{\mathrm{a}} \\
46.15 \pm 7.23^{\mathrm{a}}\end{array}$ & $\begin{array}{l}95.45 \pm 1.03^{\mathrm{b}} \\
1506.42 \pm 266.7^{\mathrm{a}} \\
81.85 \pm 27.45^{\mathrm{b}} \\
8.2 \pm 1.296^{\mathrm{a}} \\
0.169 \pm 0.073^{\mathrm{a}} \\
2.48 \pm 0.98^{\mathrm{a}} \\
0.83 \pm 0.011^{\mathrm{b}} \\
0.65 \pm 0.067^{\mathrm{a}} \\
0.33 \pm 0.058^{\mathrm{a}} \\
0.52 \pm 0.106^{\mathrm{a}} \\
0.42 \pm 0.197^{\mathrm{a}} \\
0.59 \pm 0.47^{\mathrm{a}} \\
56.74 \pm 9.79^{\mathrm{a}}\end{array}$ & $\begin{array}{l}97.48 \pm 0.9 \\
98 \pm 19.6 \\
263.42 \pm 110.8 \\
95.68 \pm 9.1 \\
114.56 \pm 118 \\
119.34 \pm 98.5 \\
102.09 \pm 2.9 \\
113.39 \pm 21.7 \\
122.89 \pm 39.8 \\
109.13 \pm 29.8 \\
68.54 \pm 40.8 \\
42.07 \pm 62.9 \\
122.93 \pm 39.8\end{array}$ \\
\hline $100\left[\mu \mathrm{mol} \mathrm{m}{ }^{-2} \mathrm{~s}^{-1}\right]$ & $\begin{array}{l}P_{\mathrm{N}}\left[\mu \mathrm{mol}\left(\mathrm{CO}_{2}\right) \mathrm{m}^{-2} \mathrm{~s}^{-1}\right] \\
g_{\mathrm{s}}\left[\mathrm{mol}\left(\mathrm{H}_{2} \mathrm{O}\right) \mathrm{m}^{-2} \mathrm{~s}^{-1}\right] \\
E\left[\mathrm{mmol}\left(\mathrm{H}_{2} \mathrm{O}\right) \mathrm{m}^{-2} \mathrm{~s}^{-1}\right] \\
\mathrm{F}_{\mathrm{v}} / \mathrm{F}_{\mathrm{m}} \\
\mathrm{F}_{\mathrm{v}} / \mathrm{F}_{\mathrm{m}} \\
\Phi_{\mathrm{PSII}} \\
\mathrm{qP} \\
\mathrm{q}_{\mathrm{N}} \\
\mathrm{NPQ} \\
\text { ETR }\left[\mu \mathrm{mol} \mathrm{m}^{-2} \mathrm{~s}^{-1}\right]\end{array}$ & $\begin{array}{l}0.93 \pm 0.541^{\mathrm{a}} \\
0.009 \pm 0.003^{\mathrm{a}} \\
0.14 \pm 0.05^{\mathrm{a}} \\
0.84 \pm 0.012^{\mathrm{a}} \\
0.62 \pm 0.032^{\mathrm{a}} \\
0.54 \pm 0.034^{\mathrm{a}} \\
0.86 \pm 0.036^{\mathrm{a}} \\
0.67 \pm 0.072^{\mathrm{a}} \\
1.31 \pm 0.38^{\mathrm{a}} \\
22.95 \pm 1.47^{\mathrm{a}}\end{array}$ & $\begin{array}{l}2.16 \pm 0.648^{\mathrm{b}} \\
0.047 \pm 0.025^{\mathrm{b}} \\
0.75 \pm 0.39^{\mathrm{b}} \\
0.83 \pm 0.005^{\mathrm{a}} \\
0.68 \pm 0.028^{\mathrm{b}} \\
0.55 \pm 0.041^{\mathrm{a}} \\
0.8 \pm 0.044^{\mathrm{b}} \\
0.46 \pm 0.114^{\mathrm{b}} \\
0.63 \pm 0.261^{\mathrm{b}} \\
23.3 \pm 1.8^{\mathrm{a}}\end{array}$ & $\begin{array}{l}231.42 \pm 286.9 \\
549.71 \pm 262 \\
513.43 \pm 235.4 \\
99.23 \pm 1.6 \\
109.68 \pm 6.6 \\
101.9 \pm 8.9 \\
92.89 \pm 6.9 \\
69.65 \pm 16.9 \\
48.52 \pm 22.9 \\
101.54 \pm 9.1\end{array}$ \\
\hline
\end{tabular}

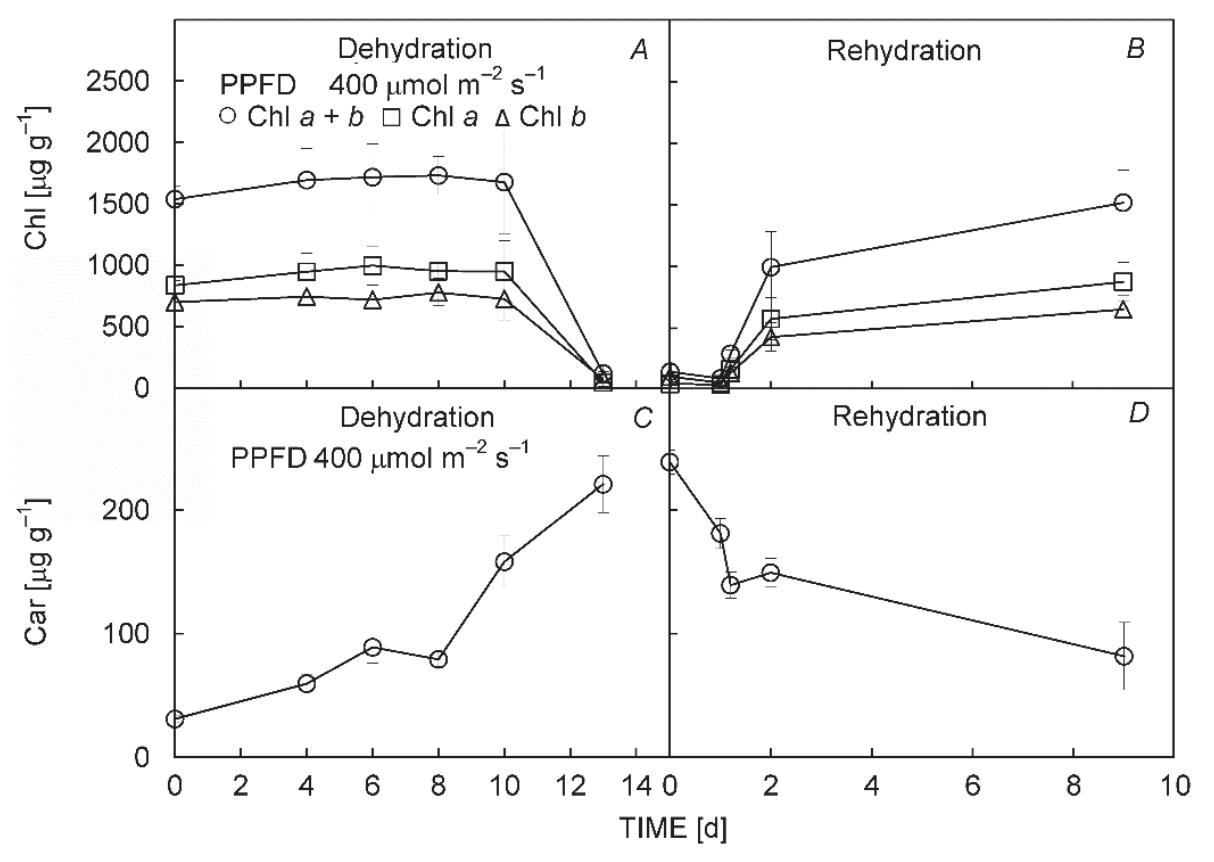

Fig. 2. Chlorophyll (Chl) $a$, Chl $b$, and $\mathrm{Chl}(a+b)(A, B)$ and carotenoids $(C, D)$ concentration in leaf pieces of $P$. purpurea during dehydration $(A, C)$ and rehydration $(B, D)$ phases under PPFD of $400 \mu \mathrm{mol} \mathrm{m} \mathrm{m}^{-2} \mathrm{~s}^{-1}$. Means $\pm \mathrm{SD}, n=3$. 


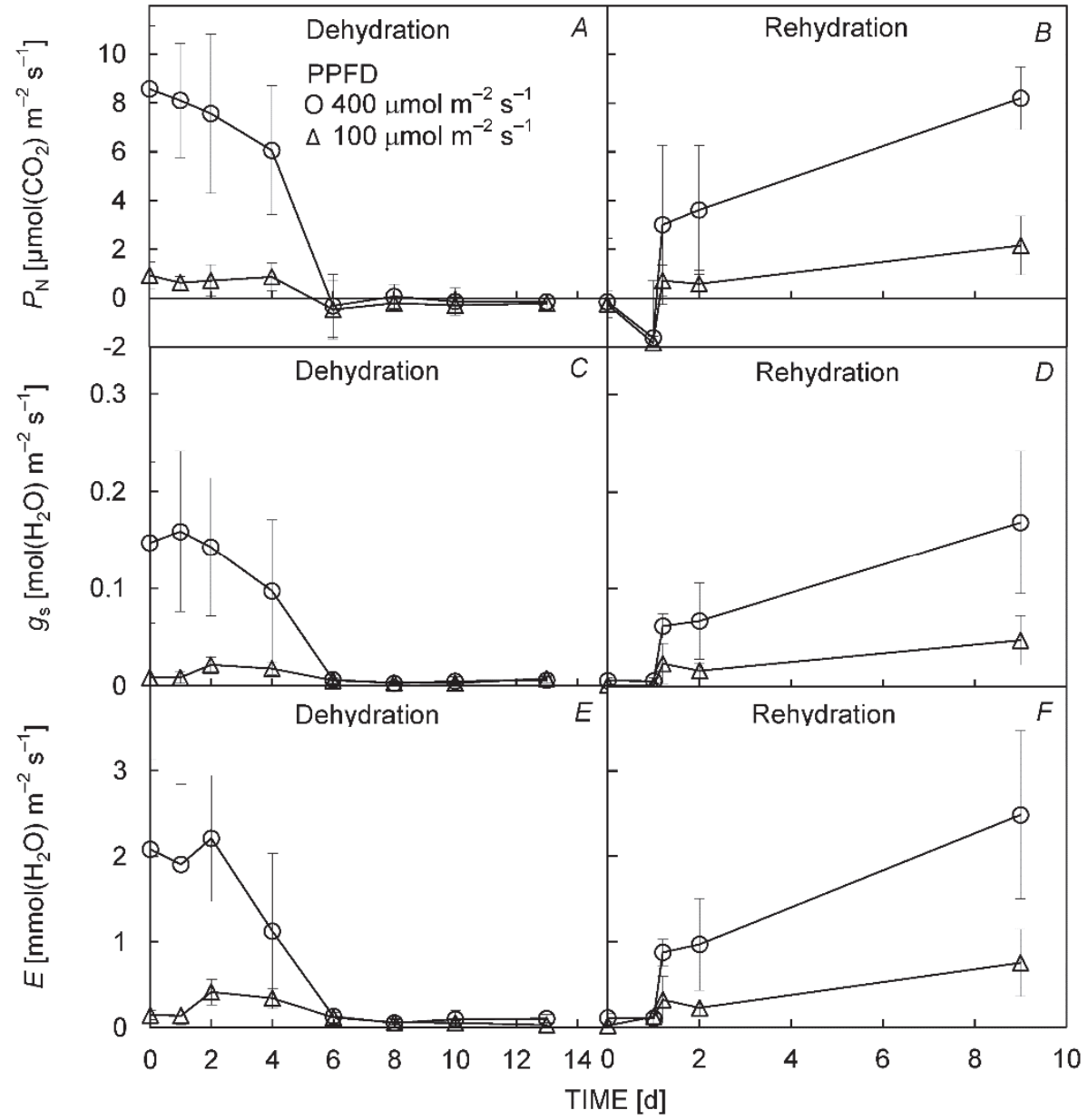

Fig. 3. Net photosynthetic rate $\left(P_{\mathrm{N}}\right)$ $(A, B)$, stomatal conductance $\left(g_{\mathrm{s}}\right)$ $(C, D)$, and transpiration rate $(E)(E, F)$ during the progress of dehydration $(A, C, E)$ and rehydration $(B, D, F)$ in $P$. purpurea under PPFD of $400 \mu \mathrm{mol}$ $\mathrm{m}^{-2} \mathrm{~s}^{-1}(\mathrm{O})$ and $100 \mu \mathrm{mol} \mathrm{m} \mathrm{m}^{-2} \mathrm{~s}^{-1}(\Delta)$. Means $\pm \mathrm{SD}, n=6$.
With rehydration, $\mathrm{F}_{\mathrm{v}} / \mathrm{F}_{\mathrm{m}}$ (Fig. $4 B$ ), $\Phi_{\text {PSII }}$ (Fig. 4D), $\mathrm{F}_{\mathrm{v}}{ }^{\prime} / \mathrm{F}_{\mathrm{m}}{ }^{\prime}$ (Fig. $4 F$ ), and ETR (Fig. 4H) increased significantly within the first $24 \mathrm{~h}$ and, after nine days, all parameters achieved complete recovery compared with the control conditions (Table 1).

The $\mathrm{q}_{\mathrm{P}}$ (Fig. 5A) decreased, while the $\mathrm{q}_{\mathrm{N}}$ (Fig. 5C) and NPQ (Fig. $5 E$ ) increased during dehydration, all of them in the dual transition phase as observed for the quantum efficiency parameters (Fig. 4). On 13 DD, some $\mathrm{q}_{\mathrm{P}}$ and $\mathrm{q}_{\mathrm{N}}$ replication values changed abruptly, clearly due to

\section{Discussion}

The general pattern of leaf gas exchange during desiccation-rehydration cycle was generally in agreement with earlier reports on the same and others PDT species (Meguro et al. 1977, Tuba et al. 1994, Aidar et al. 2010). Restrictions of $g_{\mathrm{s}}$ seemed to be the principal cause for the initial decrease in $P_{\mathrm{N}}$ during progressive dehydration of $P$. purpurea. This was caused probably due to limited gas diffusion to the intercellular spaces as some authors also suggest for HDT species (Schwab et al. 1989, Peeva and computation of higher values of basal fluorescence compared to maximum fluorescence under very low $\mathrm{Chl}$ content, which has no physiological significance. This effect did not occur with NPQ, which approximated zero after complete dehydration.

After 9 DR, qp recovered completely (Fig. $5 B$ ), but $\mathrm{q}_{\mathrm{N}}$ (Fig. 5D) and NPQ (Fig. 5F) became lower than those observed in the control under fully hydrated condition under both light treatments.

Cornic 2009). Concomitantly, early decrease of $F_{v}{ }^{\prime} / F_{m}{ }^{\prime}$ under the higher PPFD and under partial stomata closure was associated with the increase of nonphotochemical quenching, indicating the decrease in the sink capacity for electrons. Under conditions of low $\mathrm{CO}_{2}$ assimilation, light becomes excessive causing an excess of protons in the lumen and activating nonphotochemical quenching as heat dissipation by xantophyll cycle (Saccardy et al. 1998). Despite the enhanced nonphotochemical quenching in the 


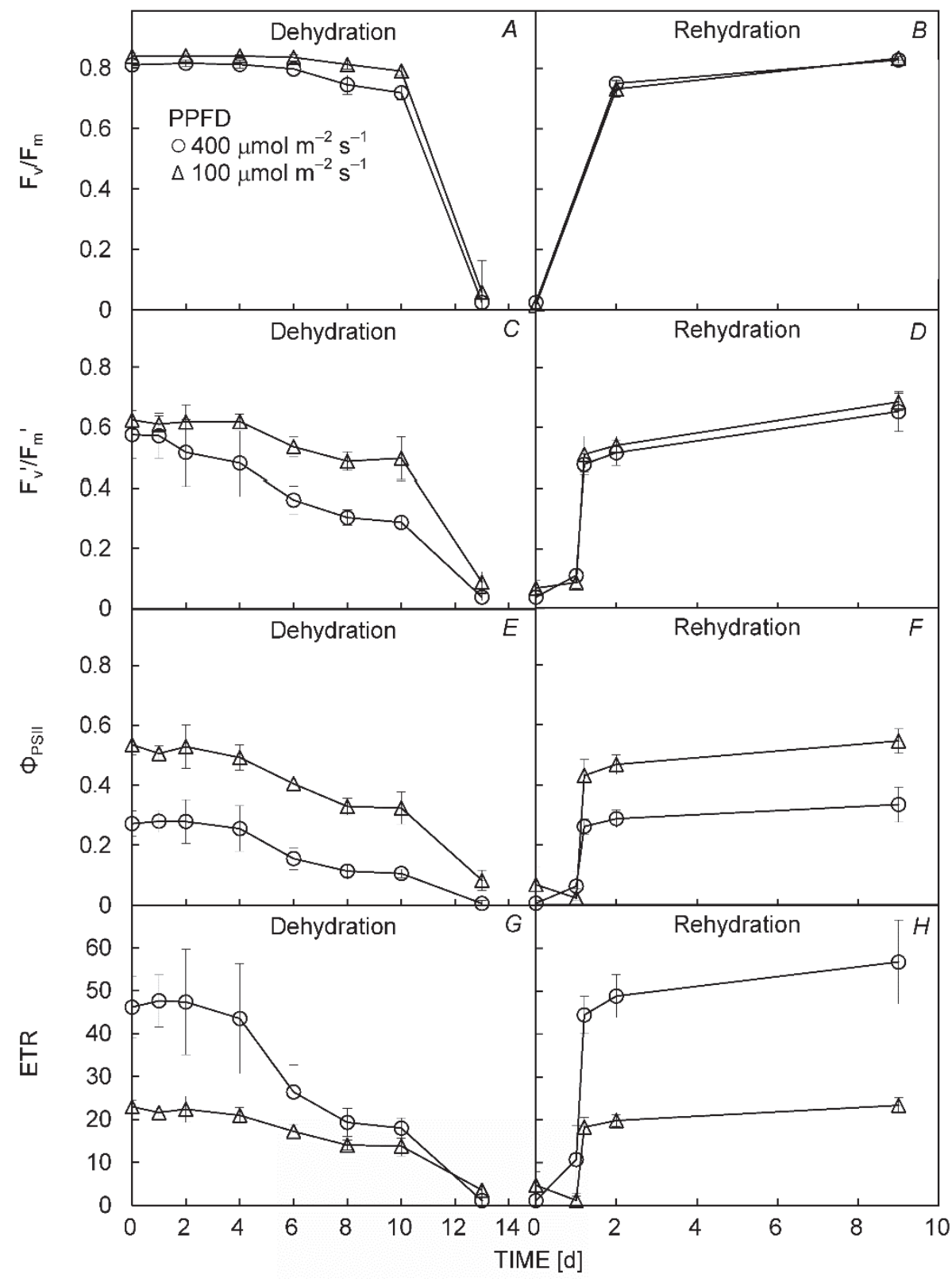

Fig. 4. Maximum quantum yield of the PSII photochemistry $\left(\mathrm{F}_{\mathrm{v}} / \mathrm{F}_{\mathrm{m}}\right)$ $(A, B)$, intrinsic quantum yield of the light-adapted state $\left(\mathrm{F}_{\mathrm{v}}{ }^{\prime} / \mathrm{Fm}_{\mathrm{m}}\right)(C, D)$, actual quantum yield of PSII photochemistry (ФPSII) $(E, F)$, and electron transport rate (ETR) $(G, H)$ during the progress of dehydration $(A, C, E, G)$ and rehydration $(B, D, F, H)$ in $P$. purpurea under PPFD of $400 \mu \mathrm{mol} \mathrm{m} \mathrm{m}^{-2} \mathrm{~s}^{-1}(\circ)$ and $100 \mu \mathrm{mol} \mathrm{m}^{-2} \mathrm{~s}^{-1}(\Delta)$. Means $\pm \mathrm{SD}$, $n=6$. light, high $\mathrm{F}_{\mathrm{v}} / \mathrm{F}_{\mathrm{m}}$ measured in predawn conditions indicated the reversibility of the heat dissipation processes and the effective protection against photoinhibition during the first days of irrigation ceasing.

After complete stomata closure, low intercellular concentration of $\mathrm{CO}_{2}$ limited carboxylation by ribulose-1,5bisphosphate carboxylase/oxygenase (Rubisco) and, consequently, the regeneration of ribulose-1,5-bisphosphate (RuBP). Since the decrease in the RuBP regeneration can limit the operation of Calvin cycle (Medrano et al. 2002), it is expected a decrease in the proportion of opened PSII reaction centers as a consequence of an impediment to the flow of electrons from PSII to PSI. This was confirmed by partial decrease of $\mathrm{q}_{\mathrm{P}}$ and ETR, respectively. However, $\mathrm{q}_{\mathrm{P}}$ sustained relatively high after stomata closure. Probably, this could be explained by reassimilation of the $\mathrm{CO}_{2}$ lost by respiration, at least until the $10 \mathrm{DD}$. This could be supported by the maintenance of $\Phi_{\text {PSII }}$ values that indicate the proportion of absorbed energy used in photochemistry and correlate with the quantum yield of $\mathrm{CO}_{2}$ (Fryer et al. 1998). However, under $\mathrm{CO}_{2}$ limitation, the photorespiratory carbon oxidation (PCO) cycle must be also involved in the maintenance of electron flow (Lawlor and Cornic 2002). Besides this, alternative electron flow, such as cyclic electron flow around PSI and water-water reactions, can also occur as additional ways to prevent oxidative stress during dehydration caused by excessive light (Endo and Asada 2002). The high resistance of electron transport chain in thylakoids was consistent with papers reporting the electron transport insensitive to a $50 \%$ decrease in the 


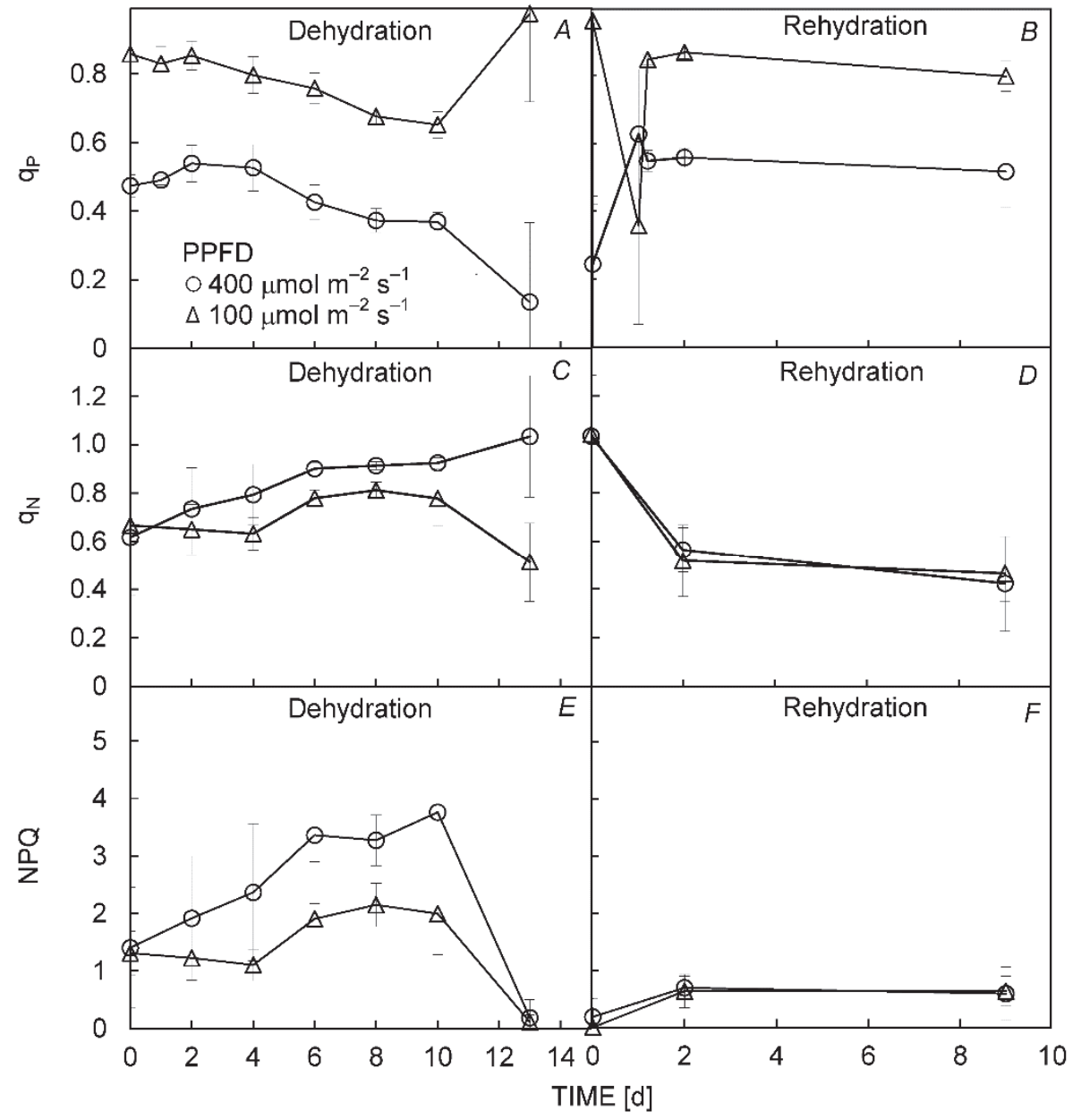

Fig. 5. Photochemical quenching coefficient (qp) $(A, B)$, nonphotochemical quenching coefficient $\left(\mathrm{q}_{\mathrm{N}}\right)$ $(C, D)$, and Stern-Volmer nonphotochemical quenching $(E, F)$ during the progress of dehydration $(A, C, E)$ and rehydration $(B, D, F)$ in $P$. purpurea under PPFD of $400 \mu \mathrm{mol} \mathrm{m} \mathrm{m}^{-2} \mathrm{~s}^{-1}(\mathrm{O})$ and $100 \mu \mathrm{mol} \mathrm{m}^{-2} \mathrm{~s}^{-1}(\Delta)$. Means \pm $\mathrm{SD}, n=6$. leaf RWC (Cornic et al. 1992, Lawlor and Cornic 2002). Studies on resurrection plants also suggested that Calvin cycle enzymes are more affected by dehydration than membrane-bound, electron transport reactions (Schwab et al. 1989, Georgieva et al. 2007).

Photochemistry maintained for an extended time after stomata closure enables rapid $P_{\mathrm{N}}$ recovery if water becomes available and stomata reopen. Obviously, if water deficit persists, components of the photosynthetic apparatus can be damaged. It was verified by the decrease of predawn $\mathrm{F}_{\mathrm{v}} / \mathrm{F}_{\mathrm{m}}$ early under the high PPFD, indicating the occurrence of chronic photoinhibition (Osmond 1994). When potted, $P$. purpurea usually showed a lower rate of dehydration than others sympatric PDT species, such as Vellozia candida (Velloziaceae) (under similar contidions of body size, soil volume, and climatic condition). This could be possible probably due to a thicker wax layer on $P$. purpurea leaves, or lower $g_{\mathrm{s}}$, or both, compared with $V$. candida. Consequently, $P$. purpurea has higher probability to benefit from next rainfall and recover from the incomplete desiccation faster than $V$. candida. This implies that $P$. purpurea kept the metabolism active longer after stomata closure during dehydration, although it predisposes the leaves to be damaged by light if the Chl content is maintained. Thus, the higher irradiance the plants are exposed to, the higher probability of photooxidative damage under conditions of incomplete desiccation. As photooxidation of photosynthetic apparatus can decrease the efficiency of carbon gain, its repetitive occurrence during incomplete dehydration-rehydration cycles could be one of the reasons why $P$. purpurea is excluded from more light-exposed sites.

The plant can avoid dehydration with low $g_{\mathrm{s}}$ only if different mechanisms can be induced for the desiccation tolerance. Thus, the transiently negative $P_{\mathrm{N}}$ after stomata closure is consistent during dehydration with the process called desiccation respiration and it can be explained by an effective rise in respiration rate according to Tuba et al. (1997). These authors suggest that this phenomenon is related to energy supply to control disassembly of the internal membrane structures in PDT species. However, as detected immediately after stomata closure, desiccation respiration also starts providing energy to induce desiccation tolerance mechanisms.

Chl loss and dismantling photosynthetic apparatus seems to be the last process to prepare tolerant leaf tissues for desiccation. $P$. purpurea occurs naturally at the sites subjected to periods of water deficit for several months. Thus, the complete loss of Chl during dehydration is important to prevent its interaction with light and 
photooxidative damage in desiccated leaf tissues. In general, PDT plants are found in intermittently arid habitats under high irradiances (Tuba and Lichtenthaler 2011). Thus, the advantage of $\mathrm{Chl}$ loss to prevent pigmentlight interaction in the desiccated state is consistent with the needs of DT plants to colonize more exposed sites in rock outcrops (Sherwin and Farrant 1996). On the other hand, HDT plants retain most of their photosynthetic apparatus and they usually survive relatively shorter drought periods in the desiccated state (Tuba and Lichtenthaler 2011). In this case, light may cause a cumulative damage in the dried green leaves decreasing gradually the ability to recover after long drought periods. Therefore, HDT plants are found in more shady habitats than PDT species. Concluding, Chl loss in PDT plants is important for the maintenance of leaf tissues viability in the desiccated state in long-term, preventing accumulative photooxidation.

During rehydration, all components of photosynthetic apparatus together with Chl must be renewed for the reconstitution of functional PSII antennae and reaction centers in PDT species (Pérez et al. 2011). Any damage caused by light during dehydration phase must be repaired to recover fully the photosynthetic apparatus during rehydration. Our experiments proved that higher irradiance, and therefore more intense photoinhibition, during dehydration phase did not affect the ability to recover $P_{\mathrm{N}}$ during rehydration. On the other hand, $\mathrm{q}_{\mathrm{P}}$ and ETR recovered more rapidly under higher PPFD during $24 \mathrm{~h}$ of rehydration, probably due to a higher rate of $\mathrm{Chl}$ resynthesis under such conditions. These results indicate that PDT mechanism is effective in light protection and recovery of $P$. purpurea from desiccation.

Progressive accumulation of Car during dehydration

\section{References}

Aidar, S.T., Meirelles, S.T., Pocius, O., et al.: Desiccation tolerance in Pleurostima purpurea (Velloziaceae). - Plant Growth Regul. 62: 193-202, 2010.

Bilger, W., Björkman, O.: Role of the xanthophyll cycle in photoprotection elucidated by measurements of light-induced absorbance changes, fluorescence and photosynthesis in leaves of Hedera canariensis. - Photosynth. Res. 25: 173-185, 1990.

Cornic, G., Ghashghaie, J., Genty, B., Briantais, J.M.: Leaf photosynthesis is resistant to a mild drought stress. Photosynthetica 27: 295-309, 1992.

Degl'Innocenti, E., Guidi, L., Stevanovic, B., Navari, F.: $\mathrm{CO}_{2}$ fixation and chlorophyll a fluorescence in leaves of Ramonda serbica during a dehydration-rehydration cycle. - J. Plant Physiol. 165: 723-733, 2008.

Dinakar, C., Djilianov, D., Bartels, D.: Photosynthesis in desiccation tolerant plants: Energy metabolism and antioxidative stress defense. - Plant Sci. 182: 29-41, 2012.

Endo, T., Asada, K.: Photosystem I and photoprotection: cyclic electron flow and water-water cycle. - In: Demmin-Adams, B., Adams, W.W.III, Matoo, A.K. (ed.): Photoprotection, Photoinhibition, Gene Regulation and Environment. Pp. 205-221. indicated their protective role against light damage in leaf tissues of $P$. purpurea. These pigments can absorb excessive light instead of $\mathrm{Chl}$ and act as antioxidants preventing the formation of superoxide radical (Smirnoff 1993). Contrary to our present results, Car content remained constant despite dehydration-rehydration under direct

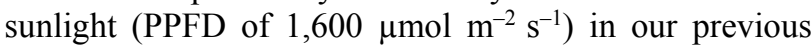
work (Aidar et al. 2010). It seems that Car content in $P$. purpurea depends on the PPFD under which the plants grow. However, when they grow under PPFD below a certain limit, the Car content can be regulated by dehydration. In others PDT species studied, Car also did not increase during dehydration (Sherwin and Farrant 1998, Farrant et al. 2003). This might be associated with growth conditions or with the presence of other protective pigments.

Interestingly, while Car content did not decrease to the control values after several days of rehydration, $\mathrm{q}_{\mathrm{N}}$ and NPQ became comparatively lower suggesting acclimation. As Car are quenching triplet-state Chl, maintaining their high content could be important even after rehydration phase due to safe recovery of $\mathrm{Chl}$ content until the steady state is established.

Despite the susceptibility of photosynthesis to photoinhibition during dehydration, two different light intensities did not affect the ability of $P$. purpurea to recover normal photosynthetic activity after rehydration. PDT poikilochlorophylly strategy is important both as the way to prevent light-Chl interaction in the desiccated state for a long period, as well as to renew the photosynthetic apparatus during rehydration regardless of photoinhibition suffered during dehydration. Further research is needed for a detailed characterization of the exact mechanisms involved in light protection of $P$. purpurea.
Springer, The Netherlands 2002.

Farrant, J.M., Willigen, C.V., Loffell, D.A., Bartsch, S., Whittaker, A.: An investigation into the role of light during desiccation of three angiosperm resurrection plants. - Plant Cell Environ. 26: 1275-1286, 2003.

Fryer, M.J., Andrews, J.R., Oxborough, K., Blowers, D.A., Baker, N.R.: Relationship between $\mathrm{CO}_{2}$ assimilation, photosynthetic electrons transport, and active $\mathrm{O}_{2}$ metabolism in leaves of maize in the field during periods of low temperature. - Plant Physiol. 116: 571-580, 1998.

Gaff, D.F.: Desiccation tolerant plants in South America. Oecologia 74: 133-136, 1987.

Genty, B., Briantais, J.M., Baker, N.R.: The relationship between quantum yield of photosynthetic electron transport and quenching chlorophyll fluorescence. - Biochim. Biophys. Acta. 990: 87-92, 1989.

Georgieva, K., Lenk, S., Buschmann, C.: Responses to the resurrection plant Haberlea rhodopensis to high irradiance. Photosynthetica 46: 208-215, 2008.

Georgieva, K., Szigeti, Z., Sarvari, E., Gaspar, L., Maslenkova, L., Peva, V., Peli, E., Tuba, Z.: Photosynthetic activity of 
homoiochlorophyllous desiccation tolerant plant Haberlea rhodopensis during dehydration and rehydration. - Planta 225: 955-964, 2007.

Hambler, D.J.: A poikilohydrous, poikilochlorophyllous angiosperm from Africa. - Nature 191: 1415-1416, 1961.

Kitajima, M., Butler, W.L.: Quenching of chlorophyll fluorescence and primary photochemistry in chloroplasts by dibromothymoquinone. - Biochim. Biophys. Acta 376: 105-115, 1975.

Lawlor, D.W., Cornic, G.: Photosynthetic carbon assimilation and associated metabolism in relation to water deficits in higher plants. - Plant Cell Environ. 25: 275-294, 2002.

Lichtenthaler, H.K., Wellburn, A.R.: Determinations of total carotenoids and chlorophylls $a$ and $b$ of leaf extracts in different solvents. - Biochem. Soc. Trans. 11: 591-592, 1983.

Medrano, H., Escalona, J.M., Bota, J., Gulias, J., Flexas, J.: Regulation of photosynthesis of $\mathrm{C} 3$ plants in response to progressive drought: stomatal conductance as a reference parameter. - Ann. Bot. 89: 895-905, 2002.

Meguro, M., Joly, C.A., Bittencourt, M.M.: [Water stress and some aspects of the physiological behaviour in Xerophyta plicata Spreng. - Velloziaceae.] - Bol. Fac. Filos. Cienc. Let. Univ. Sao Paulo Ser. Bot. 5: 27-42, 1977. [In Portuguese]

Meirelles, S.T., Mattos, E.A., Silva, A.C.: Potential desiccation tolerant vascular plants from southeastern Brazil. - Pol. J. Environ. Stud. 6: 17-21, 1997.

Meirelles, S.T., Pivello, V.R., Joly, C.A.: The vegetation of granite rock outcrops in Rio de Janeiro, Brazil, and the need for its protection. - Environ. Conserv. 26: 10-20, 1999.

Osmond, C.B.: What is photoinhibition? Some insights from comparisions of shade and sun plants. - In: Baker, N.R., Bowyer, J.R. (eds.): Photoinhibition of Photosynthesis, from Molecular Mechanisms to the Field. $1^{\text {st }}$ ed., Pp. 1-24. Bios Scientific Publishers, Oxford 1994.

Peeva, V., Cornic, G.: Leaf photosynthesis of Haberlea rhodopensis before and during drought. - Environ. Exp. Bot. 65: 310318, 2009.

Péli, E.R., Mihailova, G., Petkova, S., Tuba, Z., Georgieva, K.: Differences in physiological adaptation of Haberlea rhodopensis Friv. leaves and roots during dehydration-rehydration cycle. - Acta Physiol. Plant. 34: 947-955, 2012.

Pérez, P., Rabnecz, G., Laufer, Z., Gutiérrez, D., Tuba, Z., Martínez-Carrasco, R.: Restoration of photosystem II photochemistry and carbon assimilation and related changes in chlorophyll and protein contents during the rehydration of desiccated Xerophyta scabrida leaves. - J. Exp. Bot. 62: 895-905, 2011.

Rascio, N., La Rocca, N.: Resurrection plants: the puzzle of surviving extreme vegetative desiccation. - Crit. Rev. Plant Sci. 24: 209-225, 2005.

Saccardy, K., Pineau, B., Roche, O., Cornic, G.: Photochemical efficiency of photosystem II and xanthophyll cycle components in Zea mays leaves exposed to water stress and high light. Photosynth. Res. 56: 57-66, 1998.

Schwab, K.B., Schreiber, U., Heber, U.: Response of photosynthesis and respiration of resurrection plants to desiccation and rehydration. - Planta 177: 217-227, 1989.

Sherwin, H.W., Farrant, J.M.: Differences in rehydration of three desiccation-tolerant angiosperm species. - Ann. Bot. 78: 703$710,1996$.

Sherwin, H.W., Farrant, J.M.: Protection mechanisms against excess light in the resurrection plants Craterostigma wilmsii and Xerophyta viscosa. - Plant Growth Regul. 24: 203-210, 1998.

Smirnoff, N.: Tansley Review No. 52. The role of active oxygen in the response of plants to water deficit and desiccation. - New Phytol. 125: 27-58, 1993.

Tuba, Z., Lichtenthaler, H.K.: Ecophysiology of homoiochlorophyllous and poikilochlorophyllous desiccation-tolerant plants and vegetations. - In: Lüttge, U., Beck, E., Bartels, D. (eds.): Plant Desiccation Tolerance. Ecological Studies 215, Pp. 157-183. Springer-Verlag, Berlin - Heidelberg 2011.

Tuba, Z., Lichtenthaler, H.K., Csintalan, Z., Nagy, Z., Szente, K.: Reconstitution of chlorophylls and photosynthetic $\mathrm{CO}_{2}$ assimilation upon rehydration of the desiccated poikilochlorophyllous plant Xerophyta scabrida (Pax) Th. Dur. et Schinz. - Planta 192: 414-420, 1994.

Tuba, Z., Proctor, M.C.F., Csintalan, Z.: Ecophysiological responses of homoiochlorophyllous and poikilochlorophyllous desiccation tolerant plants: a comparison and an ecological perspective. - Plant Growth Regul. 24: 211-217, 1998.

Tuba, Z., Smirnoff, N., Csintalan, Z., Nagy, Z., Szente, K.: Respiration during slow desiccation of the poikilochlorophyllous desiccation tolerant plant Xerophyta scabrida at present-day $\mathrm{CO}_{2}$ concentrations. - Plant Physiol. Biochem. 35: 381-386, 1997.

Turner, N.C.: Techniques and experimental approaches for the measurement of plant water status. - Plant Soil 58: 339-366, 1981.

von Caemmerer, S., Farquhar, G.D.: Some relationships between the biochemistry of photosynthesis and the gas exchange of leaves. - Planta 153: 376-387, 1981.

van Kooten, O.V., Snel, J.F.H.: The use of chlorophyll fluorescence nomenclature in plant stress physiology. - Photosynth. Res. 25: 147-150, 1990. 